\title{
Apocalyptic horsemen of geriatric oncology
}

Considering the processes we encounter and must overcome to reduce the burden of Geriatric Oncology, I am reminded of the scriptural description of the Four Horsemen of the Apocalypse, War, Pestilence, Famine, and Death. All are synergistic and portend devastating outcomes. The Apocalyptic Horsemen that we must engage and thwart in Geriatric Oncology, include Genomic Infidelity, Cellular Senescence, Inflammaging and Diabesity.

Genomic Infidelity, including DNA mutagenesis, rearrangement and epigenetic changes, continuously increases over the lifespan. It provides the enabling, disruptive background for almost all malignant transformation $(1,2)$. These processes essentially throw the switches that result in oncogene activation and inactivation of tumor suppressor genes. While extensive DNA Damage Response Pathways and Epigenetic Regulatory Systems exist to counteract these changes, their inexorable progression leads to cancer as a common disease of older adults (3).

Cellular senescence, which may be associated with mutagenesis, as well as with cumulative environmental influences, leads to a number of age-associated phenotypes that significantly impact geriatric oncology. These include immuno-senescence, myo-senescence, sarcopenia, and the senescence associated secretory phenotype (SASP). Immuno-senescence results in loss and/or alterations in the immune system that may contribute to age-associated declines in immuno surveillance leading to a permissive milieu for tumor growth and increased susceptibility to infectious organisms. Senescence of muscle satellite cells accompanied by inadequate nutrition and physical activity, may contribute to decreases in skeletal muscle mass resulting in age-associated sarcopenia (4). The latter can lead to frailty, falls, functional decline, and death (5). At the same time, sarcopenia can interfere with patient tolerability of cancer therapies (6). Yet another consequence of senescence is the SASP, in which cells lose their proliferative capacity, and increase their secretion of inflammatory cytokines, many of which may amplify tumor growth supportive factors in the tumor microenvironment (7-9).

Inflammaging has been identified as age-associated chronic, sterile, low-grade inflammation that occurs in response to endogenous cell debris and metabolic errors. It may particularly occur in pathways that mediate gut-liver, gut-brain, and/or gutadipose tissue communication and interactions (10). Unlike classic acute inflammation, which is usually targeted at destroying foreign pathogenic organisms, and then terminates once the pathogens are eliminated, inflammaging is low-grade and ongoing (11). Consequences, of inflammaging include synthesis and release of cytokines including TNF, IL-1, IL-6, and IL-8, as well as epigenetic changes leading to accelerated biological aging as demonstrated by altered patterns of DNA methylation (10).

Diabesity denotes the expanding worldwide prevalence of obesity, its association with increased incidence of diabetes and the pandemic proportions of this problem in the older adult population (12-15). The consequent metaflammation (metabolic triggered inflammation), as well as the accompanying hormonal dysregulation may promote tumor growth and impact its trajectory (11). Like inflammaging, metaflammation is a low-grade, chronic, sterile inflammation, brought about mostly by expansion of adipose tissue with macrophage infiltration and activation (16).

In addition to releasing the cytokines noted above, adipocyte-macrophage interactions release a host of adipocytokines, which may further promote tumor growth in older obese adults (17). Diabesity also contributes to hormonal changes, such as increased insulin and insulin-like growth factors, as well as increased conversion of androgens to estrogens, all of which may accelerate tumor growth (18). Moreover, metaflammation further contributes to inflammaging, both of which contribute to sarcopenia and sarcopenic obesity.

Certainly, all of these processes are redundantly interactive and synergistic. Importantly however, their rates of development can be controlled and their effects can be at least partially mitigated by limiting exposure to mutagens, such as tobacco, alcohol, talc, and irradiation. In addition, lifelong adherence to recommended guidelines for diet, nutrition, and physical activity appear to slow many of these processes (19). Notably, Diabesity appears to be the most controllable by behavioral modification.

This issue of TCR features a series of articles on the impact of obesity, diabetes, and cancer in the older adult population, focuses on providing a better understanding of the processes noted above, how they may influence cancer promotion and progression, and how they may be mitigated to reduce cancer incidence and its comorbidities. The article by Muss, Smitherman, Wood et al., provides an assessment of $\mathrm{P}^{16}$ as a marker of biological aging (20). Hassan, Queen, and Cao, detail the impact of enhanced environment on cancer development and its mediation by a hypothalamic-sympathoneural-adipocyte axis (21). Xu and Rogers, address immune regulation of cancer and how it is impacted by physical activity and energy restriction (22). The article by Qiang, Lipscombe, and Lega, provide important insights into mechanisms and consequences 
of diabesity (23). Finally, Ligibel, Schmitz, and Berger, describe mechanisms and consequences of sarcopenia, particularly those that accompany cancer and suggest the need for studies for its more effective treatment (24). Overall, these articles provide an important outline of the need for increased translational research to mitigate the impact of cancer in the geriatric population.

\section{Acknowledgments}

Funding: The author declared receipt of the following financial support during research, authorship, and/or publication of this article; P20 CA233216, P30 CA043703, P50 CA150964, U54 CA163060, and the Hanna-Payne Professorship in Experimental Medicine.

\section{Footnote}

Provenance and Peer Review: This article was commissioned by the editorial office, Translational Cancer Research for the series "Energy Balance, Aging, Obesity, and Cancer". The article did not undergo external peer review.

Conflicts of Interest: The author has completed the ICMJE uniform disclosure form (available at http://dx. doi. org/10. 21037/tcr2019-eaoc-06). The series "Energy Balance, Aging, Obesity, and Cancer" was commissioned by the editorial office without any funding or sponsorship. NAB served as the unpaid Guest Editor of the series, and serves as an unpaid associate editor-in-chief of Translational Cancer Research from Sep 2019 to Aug 2024. The author has no other conflicts of interest to declare.

Ethical Statement: The author is accountable for all aspects of the work in ensuring that questions related to the accuracy or integrity of any part of the work are appropriately investigated and resolved.

Open Access Statement: This is an Open Access article distributed in accordance with the Creative Commons AttributionNonCommercial-NoDerivs 4.0 International License (CC BY-NC-ND 4.0), which permits the non-commercial replication and distribution of the article with the strict proviso that no changes or edits are made and the original work is properly cited (including links to both the formal publication through the relevant DOI and the license). See: https://creativecommons.org/ licenses/by-nc-nd/4.0/.

\section{References}

1. Hanahan D, Weinberg RA. Hallmarks of cancer: the next generation. Cell 2011;144:646-74.

2. Garraway LA, Lander ES. Lessons from the cancer genome. Cell 2013;153:17-37.

3. Berger NA, Savvides P, Koroukian SM, et al. Cancer in the elderly. Trans Am Clin Climatol Assoc 2006;117:147-55; discussion 55-6.

4. Snijders T, Parise G. Role of muscle stem cells in sarcopenia. Curr Opin Clin Nutr Metab Care 2017;20:186-90.

5. Cruz-Jentoft AJ, Bahat G, Bauer J, et al. Sarcopenia: revised European consensus on definition and diagnosis. Age Ageing 2019;48:16-31.

6. Prado CM, Baracos VE, McCargar LJ, et al. Sarcopenia as a determinant of chemotherapy toxicity and time to tumor progression in metastatic breast cancer patients receiving capecitabine treatment. Clin Cancer Res 2009;15:2920-6.

7. Campisi J. Senescent cells, tumor suppression, and organismal aging: good citizens, bad neighbors. Cell 2005;120:513-22.

8. Coppé JP, Desprez PY, Krtolica A, et al. The senescence-associated secretory phenotype: the dark side of tumor suppression. Annu Rev Pathol 2010;5:99-118.

9. Tchkonia T, Zhu Y, van Deursen J, et al. Cellular senescence and the senescent secretory phenotype: therapeutic opportunities. J Clin Invest 2013;123:966-72.

10. Franceschi C, Garagnani P, Parini P, et al. Inflammaging: a new immune-metabolic viewpoint for age-related diseases. Nat Rev Endocrinol 2018;14:576-90.

11. Antonelli M, Kushner I. It's time to redefine inflammation. FASEB J 2017;31:1787-91.

12. Farag YM, Gaballa MR. Diabesity: an overview of a rising epidemic. Nephrol Dial Transplant 2011;26:28-35.

13. Wells JCK. The diabesity epidemic in the light of evolution: insights from the capacity-load model. Diabetologia 2019;62:1740-50. 
14. Peralta M, Ramos M, Lipert A, et al. Prevalence and trends of overweight and obesity in older adults from 10 European countries from 2005 to 2013. Scand J Public Health 2018;46:522-9.

15. Flegal KM, Carroll MD, Ogden CL, et al. Prevalence and trends in obesity among US adults, 1999-2008. JAMA 2010;303:235-41.

16. Hotamisligil GS. Inflammation, metaflammation and immunometabolic disorders. Nature 2017;542:177-85.

17. Berger NA. Obesity and Cancer Pathogenesis. Ann N Y Acad Sci 2014;1311:57-76.

18. Keri RA, Distelhorst CW, Sharifi N, et al. Hormone Effects on Tumors. In: Litwack G. editor. Hormone Signaling in Biology and Medicine. 1st edition. Cambridge, Massachusetts: Academic Press, 2020:667-93.

19. Kushi LH, Doyle C, McCullough M, et al. American Cancer Society Guidelines on nutrition and physical activity for cancer prevention: reducing the risk of cancer with healthy food choices and physical activity. CA Cancer J Clin 2012;62:30-67.

20. Muss HB, Smitherman A, Wood WA, et al. p16 a biomarker of aging and tolerance for cancer therapy. Transl Cancer Res 2020;9:5732-42.

21. Hassan QN 2nd, Queen NJ, Cao L. Regulation of aging and cancer by enhanced environmental activation of a hypothalamicsympathoneural-adipocyte axis. Transl Cancer Res 2020;9:5687-99.

22. Xu Y, Rogers CJ. Impact of physical activity and energy restriction on immune regulation of cancer. Transl Cancer Res 2020;9:5700-31.

23. Qiang JK, Lipscombe LL, Lega IC. Association between diabetes, obesity, aging, and cancer: review of recent literature. Transl Cancer Res 2020;9:5743-59.

24. Ligibel JA, Schmitz KH, Berger NA. Sarcopenia in aging, obesity, and cancer. Transl Cancer Res 2020;9:5760-71.

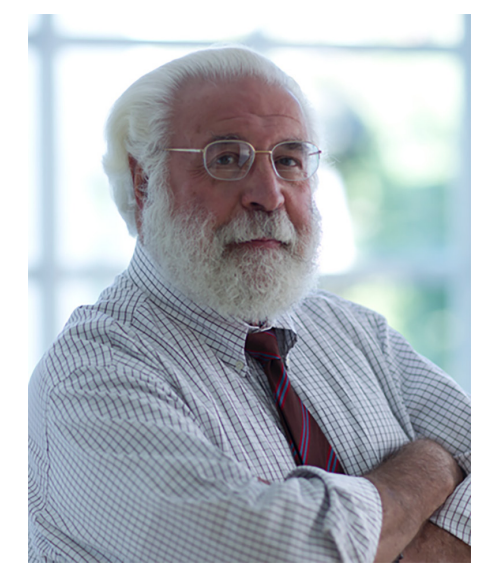

Nathan A. Berger

Nathan A. Berger, MD

Departments of Medicine, Biochemistry, Oncology, Genetics \& Genome Sciences, Center for Science, Health and Society, Case Comprehensive Cancer Center, Case Western Reserve University School of Medicine, Health Sciences Library, Cleveland, Ohio, USA.

(Email: nab@case.edu)

Submitted Jun 03, 2020. Accepted for publication Aug 11, 2020.

doi: 10.21037/tcr-2019-eaoc-06

View this article at: http://dx.doi.org/10.21037/tcr-2019-eaoc-06

Cite this article as: Berger NA. Apocalyptic horsemen of geriatric oncology. Transl Cancer Res 2020;9(9):5684-5686. doi: 10.21037/tcr-2019-eaoc-06 